\title{
The Dynamics of Unemployment and Inflation in New Keynesian Models with Two Labor Margins
} New Keynesian models for which firms unilaterally adjust labor along both
the intensive, and extensive margins usually fail to reproduce the volatility
of unemployment. In this paper, we show that a marginal wage much more
responsive than the average wage to shocks-in accordance with empiri-
cal observations-is a crucial mechanism allowing these models to repli-
cate unemployment dynamics. At the same time, the large movements of
the marginal wage are consistent with the low volatility of inflation as such
movements induce strong strategic complementarities between price setters.

JEL codes: E24, E31, E32, J64

Keywords: new Keynesian model, labor-market frictions, unemployment, inflation

Over THE PAST Two DECADES, the "New Keynesian framework" 1 - which, basically, introduces imperfect competition and nominal price stickiness within an otherwise standard Real Business Cycle core structure-has become the workhorse to study business cycle fluctuations and monetary policy. ${ }^{2} \mathrm{~A}$ prominent vintage of models has introduced search and matching frictions within this framework, allowing the analysis of the joint dynamics of unemployment and inflation. However, these models still have difficulties in generating a large volatility of the

I would like to thank Florin Bilbiie, Lawrence Christiano, Kai Christoffel, Jordi Galí, Jean-Olivier Hairault, Keith Kuester, Hervé Le Bihan, Matthieu Lemoine, Antoine Lepetit, Thomas Lubik, Julien Matheron, Arthur Poirier, Jean-Guillaume Sahuc, Tommy Sveen, Carlos Thomas, Etienne Wasmer, and Lutz Weinke for helpful comments. I am also grateful to Sanjay Chugh, the editor, and an anonymous referee for their suggestions. An earlier version of this paper circulated under the title "Credible Wage Bargaining, and the Joint Dynamics of Unemployment, and Inflation." The views expressed here are mine, and not those of the Swiss National Bank.

PIERRICK ClerC is an Economist at the Research Coordination department, Swiss National Bank (Email: pierrick.clerc@live.fr).

Received September 18, 2017; and accepted in revised form July 12, 2019.

1. This framework was alternatively called "Neomonetarist" by Kimball (1995), "New Neoclassical Synthesis" by Goodfriend and King (1997), "New Keynesian" by Clarida, Galí, and Gertler (1999), and "Neo-Wicksellian" by Woodford (2003). Here we follow the (by now) common usage and adopt the "New Keynesian" label.

2. See Galí (2008, chapter 3) for a presentation of the canonical New Keynesian model, and Galí (2018) for an assessment 10 years after the Great Recession.

Journal of Money, Credit and Banking, Vol. 53, Nos. 2-3 (March-April 2021)

(C) 2021 The Ohio State University 
unemployment rate once firms, realistically, can adjust labor along both the intensive (hours per worker) and extensive (employment) margins. ${ }^{3}$ In this paper, we argue that these difficulties stem from a particular feature of existing models, namely that they deliver roughly the same behavior for the marginal wage (the wage paid to hire an additional hour of work) and for the average wage (the hourly wage). This feature stands in sharp contrast with the empirical results of Bils (1987), who finds that the marginal wage increases much more than the average wage with hours worked in the United States.

The first contribution of the present paper is to show that a marginal wage much more responsive than the average wage is a key mechanism enabling the New Keynesian (henceforth NK) framework to replicate the dynamics of the unemployment rate. Indeed, this pattern of wages implies that the value of hiring an additional worker is itself highly responsive to shocks, thus creating a strong incentive to adjust labor along the extensive margin. One could object that large movements in the marginal wage would generate important fluctuations in the inflation rate, at odds with the small variations of this variable observed in the data. The second contribution of this paper is to stress that large movements in the marginal wage are consistent with the observed dynamics of inflation: they induce strong strategic complementarities between price setters, which in turn produce a low volatility of the inflation rate through a flat New Keynesian Phillips Curve (henceforth NKPC). We further point out that the larger the responses of the marginal wage, the stronger the strategic complementarities and the flatter the NKPC.

In order to illustrate these points, we consider an NK model (with search and matching frictions in the labor market) in which firms create jobs, determine hours per worker, and set prices. Firms also bargain with each of their workers over the average wage. Importantly, they choose hours per worker before the wage negotiation occurs, taking rationally into account that a marginal change in hours per employee will imply a change in the bargained average wage. ${ }^{4}$ The marginal and average wages are therefore not equal and can display different cyclical patterns. Moreover, employment is predetermined, so that firms can only adjust hours per worker on impact in response to shocks. ${ }^{5}$ This entails that marginal cost in the short run is defined by the marginal wage (deflated by the productivity of an additional hour of work).

Within this framework, we compare various wage bargains that provide different degrees of flexibility for the marginal and average wages. We show that the wage bargains that deliver a marginal wage much more responsive than the average wage to shocks enable this framework to replicate the high volatility of the unemployment and vacancy rates in the United States. At the same time, these wage bargains produce

3. This is particularly the case for Sveen and Weinke (2008), Christoffel and Kuester (2008), and Thomas (2011).

4. Such an assumption is notably made in the NK literature by Sveen and Weinke (2009), Thomas (2011), and Dossche, Lewis, and Poilly (2014).

5. Predetermined employment appears as a reasonable assumption as VAR evidence suggests that, on impact, employment responds little (if at all) to shocks (see Monacelli, Perotti, and Trigari 2010, Brueckner and Pappa 2012). 
a low volatility of the inflation rate through a large amount of strategic complementarities between firms. Conversely, the wage bargains that generate roughly the same pattern for the marginal and average wages completely fail to reproduce the large fluctuations in unemployment and vacancies. Hence, a main conclusion of this paper is that what matters for labor-market dynamics is not the "stickiness" of wages per se, but the stickiness of the average wage with respect to the marginal wage.

To gain some intuition, let us assume that the economy is hit by a positive demand shock. In an NK environment, most firms cannot adjust their selling price instantaneously. These firms will therefore raise production and, consequently, the volume of working hours. Given predetermined employment, they must initially increase hours of existing employees. They will subsequently raise employment if the value associated with hiring new workers increases sufficiently. The value of an additional worker positively depends on the marginal wage, as a newly hired worker allows to save extra hours (that would have been paid at this wage) of already employed workers. On the other hand, this value negatively depends on the average wage, as it is the wage at which each hour of a newly hired worker is paid. Hence, a marginal wage much more responsive than the average wage implies that the value of an additional worker rises significantly after a positive demand shock. This produces a strong incentive for firms to create jobs, leading to a large fall in unemployment.

Let us now turn to inflation dynamics. As marginal cost in the short run is equal to the marginal wage (deflated by the marginal product of hours), large movements in the marginal wage directly entail large variations in the inflation rate. But at the same time, these movements indirectly dampen inflation variations. To understand this indirect effect, take a firm contemplating a reduction in its relative price. Given predetermined employment, this firm will have to raise hours per worker to adjust production to the resulting higher demand. Anticipating the ensuing large increase in its marginal cost, the firm finally keeps its price in line with the overall price level. Such a strategic complementarity, or real price rigidity, therefore alleviates the price changes of the firms that can reset their selling prices. This indirect effect in price setting also flattens the NKPC. Crucially, the size of this effect increases with the response of the marginal wage: the larger this response, the stronger the strategic complementarities and the flatter the NKPC. Consequently, larger responses of the marginal wage imply larger movements (direct effect) along a flatter NKPC (indirect effect).

We first assess the role of the relative variations in the marginal and average wages for the reproduction of labor-market dynamics in the United States. We consider three wage bargains: the standard Nash bargaining, the credible bargaining (Hall and Milgrom 2008), and the wage norm (Hall 2005). The Nash bargaining displays flexibility for the marginal and average wages. Conversely, the wage norm generates rigidities for both wages. These two wage bargains counterfactually produce small fluctuations in the unemployment and vacancy rates. On the other hand, the credible bargaining provides a flexible marginal wage but a sticky average wage. ${ }^{6}$

6. The marginal wage is the same as under Nash bargaining, but the average wage is stickier. 
This wage bargain reproduces the high volatility of vacancies and unemployment. Hence, when firms adjust labor along both margins, a marginal wage much more responsive than the average wage is a crucial mechanism to replicate labor-market fluctuations. ${ }^{7}$

We next assess the implications of different response sizes of the marginal wage in terms of inflation dynamics. As the wage norm generates low fluctuations in the marginal wage, this wage bargain obviously reproduces the small reactions of inflation to shocks. Interestingly, although producing large movements in the marginal wage, the Nash bargaining and the credible bargaining also replicate the low volatility of inflation. For these wage bargains, the smooth adjustment of prices stems from high strategic complementarities (which flatten the NKPC). High strategic complementarities, in turn, result from the sizable movements in the marginal wage. The direct effect of large variations in the marginal wage on inflation is therefore more than offset by the indirect effect induced by these variations.

We finally investigate (alternatively) two important modifications of the baseline framework. First, we assume that firms now determine hours per worker after having negotiated over the average wage. This assumption corresponds to the Right-ToManage set-up initiated by Trigari (2006). The main implication is that the marginal wage is always equal to the average wage, as each additional hour of work can be hired at the previously bargained average wage. In this case, whatever the wage bargain implemented, the volatility of the unemployment and vacancy rates becomes negligible. Thus, when the marginal and average wages display the same responses to shocks, the fluctuations occurring in the labor market are completely at odds with the empirical evidence. Second, we assume that the average wage is posted (rather than bargained) by firms before the matching process takes place. This assumption, initially suggested by Moen (1997), is known as Competitive Search Equilibrium. In this case, the solution for the average and marginal wages converges to the solution that would occur under Nash bargaining (restricted by the Hosios condition). As under Nash bargaining both wages follow roughly the same pattern, the volatility of the unemployment and vacancy rates is accordingly low in Competitive Search Equilibrium.

\section{Related literature}

The four papers closest to the present work are those of Sveen and Weinke (2008), Christoffel and Kuester (2008), Sveen and Weinke (2009), and Thomas (2011). All these contributions adopt an NK model (with labor-market frictions) in which firms unilaterally adjust both labor margins. We do not consider frameworks in which firms

7. It is worth mentioning that the papers referred to in footnote 3 , which we discuss in greater detail below, have only considered the Nash bargaining and the wage norm. This explains why the models of these papers fail to reproduce the dynamics of the labor market. By contrast, the credible bargaining (or any other wage bargain displaying a marginal wage much more responsive than the average wage) has not been investigated in models where firms determine both margins of labor. 
and workers bargain over hours per workers as Rotemberg (2008) provides some evidence, related to the length of the workweek in the United States, against negotiations over hours per employee. ${ }^{8}$

Sveen and Weinke (2008) show that sticky wages, implemented by the wage norm, do not bring more unemployment volatility than flexible wages, implemented by the Nash bargaining. One could conclude from their results that the dynamics of wages has no impact on these of job creations and unemployment. In this paper, we argue that this conclusion would miss the point that what matters is the relative dynamics of the marginal and average wages. We stress that the wage norm and the Nash bargaining fail to reproduce labor-market facts as these wage bargains deliver roughly the same responses for the marginal and average wages. By contrast, the credible bargaining replicates labor-market dynamics by providing a marginal wage much more responsive than the average wage.

Christoffel and Kuester (2008) assume that hours per worker are determined through Right To Manage. They point out that introducing some stickiness in the average wage turns into sluggish marginal cost, generating inflation inertia. They also find a calibration, including fixed costs associated with maintaining existing jobs, which allows their framework to reproduce the volatility of the unemployment and vacancy rates. Nevertheless, this volatility collapses in the absence of the fixed costs. This result is consistent with the argument of this paper: in order to restitute labormarket dynamics, the marginal wage should exhibit much larger movements than the average wage.

Sveen and Weinke (2009) emphasize that strategic complementarities in price setting emerge when firms both bargain over the average wage and set prices. For a given pattern of the marginal wage, these complementarities imply a lower response of inflation to shocks. Here, we invoke strategic complementarities to show that sizable fluctuations in the marginal wage are consistent with small movements in the inflation rate. We further stress that the degree of strategic complementarities, and then the slope of the NKPC, depend on the responses of the marginal wage: larger responses entail stronger strategic complementarities and a flatter NKPC. Hence, large variations in the marginal wage create an incentive for firms to smooth the adjustment of prices that more than overcomes the direct impact of these variations on inflation.

With the same framework as the one used in this paper and the Nash bargaining, Thomas (2011) replicates the large volatility of the unemployment and vacancy rates. However, the responses of employment to shocks are amplified by an additional mechanism related to the introduction of money through a cash-in-advance constraint. Thomas next assumes a more standard cashless economy (associated with a Taylor rule) and finds that the volatility of unemployment and vacancies declines substantially. In this paper, we show that this framework is able to reproduce labor-market dynamics even for a cashless economy, provided that the marginal wage displays much larger movements than the average wage.

8. Trigari (2006) also notices that hours per worker are rarely the object of negotiations. Trigari (2009), however, uses the efficient bargaining framework for simplicity. 
The rest of the paper is organized as follows. In the next section, we present the model and lay a particular emphasis on the various wage bargains considered. In Section 2, we calibrate and assess its quantitative implications along the labor-market and inflation dimensions. Section 3 considers Right To Manage and Competitive Search Equilibrium. Section 4 concludes.

\section{THE MODEL}

The basic structure of the model stems from Thomas (2011). Household members supply labor services on a frictional labor market and consume differentiated goods produced by monopolistic firms. These firms set prices, create jobs, and determine hours per worker. They also bargain over the hourly wage with each worker. We depart from Thomas (2011) and other papers that use this framework by implementing alternative wage bargains. Finally, the monetary authority sets the nominal interest rate.

\subsection{Labor-Market Frictions}

Searching for a worker to fill a vacancy involves a fixed cost $\chi$. The number of new matches for each period is given by a matching function $m\left(u_{t}, v_{t}\right)$, where $u_{t}$ and $v_{t}$ represent the number of unemployed workers and the number of open job vacancies, respectively, at period $t$. As the labor force is normalized to one, $u_{t}$ and $v_{t}$ also represent the unemployment and vacancy rates.

The matching rate for unemployed workers, the job-finding rate, is given by $f\left(\theta_{t}\right) \equiv \frac{m\left(u_{t}, v_{t}\right)}{u_{t}}$. This rate increases with market tightness $\theta_{t}$, the ratio of vacancies to unemployment. The rate at which vacancies are filled is given by $q\left(\theta_{t}\right) \equiv \frac{m\left(u_{t}, v_{t}\right)}{v_{t}}$, which decreases with $\theta_{t}$.

Finally, matches are destroyed at the exogenous rate $s$ at the end of each period.

\subsection{Households}

Following Merz (1995), we assume a large representative household in which a fraction $n_{t}$ of members are employed in a measure-one continuum of firms. The remaining fraction $u_{t}=1-n_{t}$ is unemployed and searching for a job. Equal consumption across members is ensured through the pooling of incomes. The welfare of the household is given by

$$
H_{t}=u\left(c_{t}\right)-x_{h} \int_{0}^{1} n_{i t} \frac{h_{i t}^{1+\eta}}{1+\eta} d i+\beta E_{t} H_{t+1},
$$

where $c_{t}$ is a Dixit-Stiglitz aggregator of different varieties of goods, $n_{i t}$ the number of workers in firm $i \in[0,1], h_{i t}$ the number of hours worked by a worker in firm $i$, and $x_{h}$ a positive scaling parameter of disutility of work. 


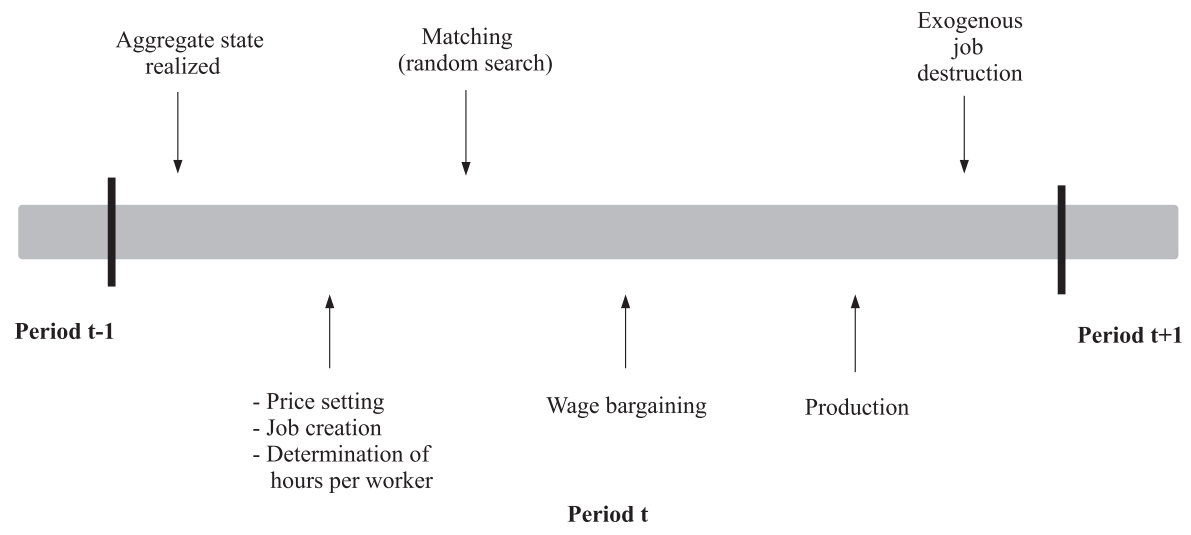

Fig 1. Timing - Baseline.

The household faces the sequence of real budget constraints:

$$
\int_{0}^{1} n_{i t} w_{i t} h_{i t} d i+\left(1-n_{i t}\right) b+\frac{\Theta_{t}}{P_{t}}+\left(1+i_{t}\right) \frac{B_{t-1}}{P_{t}} \geq c_{t}+\frac{B_{t}}{P_{t}},
$$

where $w_{i t}$ is the real hourly wage earned by a worker in firm $i, b$ is the unemployment income (including notably unemployment benefits and home production) received by unemployed members, $P_{t}$ is the price level, $B_{t-1}$ is the holdings of oneperiod nominal bonds that pay a gross nominal interest rate $\left(1+i_{t}\right)$ one period later, and $\Theta_{t}$ is a lump-sum component of income that may include dividends from the firm sector or lump-sum taxes. From now on, $w_{i t}$ will be called the real average wage.

The intertemporal optimality condition is given by the standard Euler condition:

$$
u^{\prime}\left(c_{t}\right)=\beta\left(1+i_{t}\right) E_{t}\left[\frac{P_{t}}{P_{t+1}} u^{\prime}\left(c_{t+1}\right)\right] .
$$

As usual, optimality also requires that a No-Ponzi condition be satisfied.

\subsection{Firms}

Firms set prices, post vacancies, and choose hours per worker. The wage bargain (with employees) over the real average wage is assumed to take place subsequently. Firms therefore meet the sequence of events described by Figure 1.

The firm's program. There is a measure-one continuum of firms. Each of them produces a differentiated good that is sold monopolistically. Consider a firm $i \in[0,1]$ that starts period $t$ with a continuum of workers of size $n_{i t}$. This firm posts $v_{i t}$ vacancies at cost $\chi$ and chooses $h_{i t}$ working hours for each worker at a real average wage 
$w_{i t}$. The value of the firm $i$ at period $t$ is denoted by $\Pi_{i t}$ :

$$
\Pi_{i t}=\frac{P_{i t}}{P_{t}} y_{i t}^{d}-w_{i t} h_{i t} n_{i t}-\chi v_{i t}+E_{t} \beta_{t, t+1} \Pi_{i t+1},
$$

where $P_{i t}$ is the firm's nominal price, $y_{i t}^{d}$ the demand for its good, and $\beta_{t, t+k} \equiv \beta^{k} u^{\prime}\left(c_{t+k}\right) / u^{\prime}\left(c_{t}\right)$ the stochastic discount factor between periods $t$ and $t+k$. Cost minimization by households implies that demand for each firm can be written as

$$
y_{i t}^{d}=\left(\frac{P_{i t}}{P_{t}}\right)^{-\epsilon} y_{t}^{d},
$$

where $y_{t}^{d}$ denotes aggregate demand. Vacancy posting costs are assumed to take the form of the same CES function as the one defining the consumption index. Aggregate demand is therefore given by

$$
y_{t}^{d}=c_{t}+\chi v_{t} .
$$

Labor is transformed into output by means of the following production function:

$$
y_{i t}^{s}=A_{t} n_{i t} h_{i t}^{\alpha},
$$

where $A_{t}$ is a common labor productivity shock. The log of this shock, $a_{t}=\ln A_{t}$ follows an AR(1) process, $a_{t}=\rho_{a} a_{t-1}+e_{t}^{a}$, where $e_{t}^{a}$ is an independent and identically distributed (i.i.d.) shock. The firm commits itself to meeting demand at the chosen price. This implies that the following condition should hold in every period:

$$
\left(\frac{P_{i t}}{P_{t}}\right)^{-\epsilon} y_{t}^{d}=A_{t} n_{i t} h_{i t}^{\alpha} .
$$

Given search frictions in the labor market, it is assumed that a new worker becomes productive in the following period. Employment at firm level is thus given by

$$
n_{i t+1}=(1-s) n_{i t}+q\left(\theta_{t}\right) v_{i t} .
$$

The Lagrange multipliers with respect to constraints (3) and (4) are denoted by $m c_{i t}$ and $\vartheta_{i t}$, respectively. Hence, $m c_{i t}$ represents the real marginal cost of production. Note that $m c_{i t}$ is a firm-wide variable. The firm determines the state-contingent path $\left\{h_{i t}, v_{i t}, n_{i t+1}\right\}$ that maximizes its value $\Pi_{i t}$, subject to constraints (3) and (4).

First-order conditions for the above problem read as follows:

$$
\begin{aligned}
& \partial h_{i t}: \quad m c_{i t} \alpha A_{t} h_{i t}^{\alpha-1}=w_{i t}+w_{i t}^{\prime}\left(h_{i t}\right) h_{i t}, \\
& \partial v_{i t}: \quad \frac{\chi}{q\left(\theta_{t}\right)}=\vartheta_{i t},
\end{aligned}
$$




$$
\partial n_{i t+1}: \quad \vartheta_{i t}=E_{t} \beta_{t, t+1}\left[m c_{i t+1} A_{t+1} h_{i t+1}^{\alpha}-w_{i t+1} h_{i t+1}+(1-s) \vartheta_{i t+1}\right],
$$

where $\alpha A_{t} h_{i t}^{\alpha-1}$ is the marginal product of hours, denoted by $m p h_{t}$.

The real marginal wage for a given worker in firm $i$, that is, $w_{i t}+w_{i t}^{\prime}\left(h_{i t}\right) h_{i t}$, is denoted by $\omega_{i t}$. As firms determine hours per worker before negotiating over the real average wage, they take rationally into account that a marginal change in hours per employee will imply a change in the average wage. This is reflected by the term $w_{i t}^{\prime}\left(h_{i t}\right) h_{i t}$ in the marginal wage schedule. From equation (5), the real marginal cost is given by

$$
m c_{i t}=\frac{\omega_{i t}}{m p h_{t}} .
$$

Hence, the real marginal cost is the ratio between the real marginal wage and the marginal product of hours. As employment is predetermined, increasing production in period $t$ requires raising hours per worker. The real marginal cost is therefore the cost of an additional hour per employee.

The wage bargaining. The value of a match for a given worker in firm $i$ at period $t$ is denoted by $W_{i t}$ :

$$
W_{i t}=w_{i t} h_{i t}-x_{h} \frac{h_{i t}^{1+\eta}}{(1+\eta) u^{\prime}\left(c_{t}\right)}+E_{t} \beta_{t, t+1}\left[(1-s) W_{i t+1}+s U_{t+1}\right],
$$

where the marginal disutility of labor is expressed in consumption units and $U_{t}$ is the unemployment value given by

$$
U_{t}=b+E_{t} \beta_{t, t+1}\left[f\left(\theta_{t}\right) W_{i t+1}+\left(1-f\left(\theta_{t}\right)\right) U_{t+1}\right] .
$$

The firm's value of a filled match with a given employee at period $t$ is denoted by $J_{i t}$ :

$$
J_{i t}=m c_{i t} A_{t} h_{i t}^{\alpha}-w_{i t} h_{i t}+E_{t} \beta_{t, t+1}\left[(1-s) J_{i t+1}+s V_{i t+1}\right],
$$

where $V_{i t}$ is the firm's value of a vacancy. Given equation (8), $V_{i t}=0$ in equilibrium. Hence, $U_{t}$ and $V_{i t}=0$ are the values obtained by the worker and the firm, respectively, when the match is dissolved. These values are called the outside options of the wage bargaining.

In what follows, three alternative types of negotiation over the real average wage are considered: the Nash bargaining, the credible bargaining, and the wage norm.

\section{Nash bargaining}

The Nash bargaining is traditionally applied by the search and matching literature to obtain the real wage. Here, the real average wage is determined by the Generalized Nash Solution (1953) with the outside options as threat points, that is, $U_{t}$ for the worker and $V_{i t}=0$ for the firm. The equilibrium wage satisfies the following 
surplus-sharing rule:

$$
(1-\zeta)\left(W_{i t}-U_{t}\right)=\zeta J_{i t},
$$

where $\zeta$ denotes the worker's bargaining power. Inserting for $W_{i t}, U_{t}$, and $J_{i t}$ and using equations (6) and (7) yields the following real average wage ${ }^{9}$ in firm $i$ :

$$
w_{i t}^{n b}=\zeta\left[m c_{i t} A_{t} h_{i t}^{\alpha-1}+\chi \frac{\theta_{t}}{h_{i t}}\right]+(1-\zeta)\left[\frac{b}{h_{i t}}+x_{h} \frac{h_{i t}^{\eta}}{(1+\eta) u^{\prime}\left(c_{t}\right)}\right]
$$

The real marginal wage in this firm is

$$
\omega_{i t}^{n b}=w_{i t}^{n b}+w_{i t}^{n b \prime}\left(h_{i t}\right) h_{i t}=\zeta m c_{i t} \alpha A_{t} h_{i t}^{\alpha-1}+(1-\zeta) x_{h} \frac{h_{i t}^{\eta}}{u^{\prime}\left(c_{t}\right)}
$$

Using equation (8), the real marginal wage can be rewritten as

$$
\omega_{i t}^{n b}=x_{h} \frac{h_{i t}^{\eta}}{u^{\prime}\left(c_{t}\right)} .
$$

The real marginal wage of a given worker in firm $i$ is thus equal to the worker's marginal rate of substitution between consumption and leisure.

\section{Credible bargaining}

Hall and Milgrom (2008) and Christiano, Eichenbaum, and Trabandt (2016) argue that on a frictional labor market, the surplus of a match is such that both worker and firm get higher payoffs by going to the end of the wage bargaining rather than leaving the negotiation to search for another match. The threat to leave the wage bargaining is then not credible. This means that the outside options are not credible threat points. The only credible threat is to reject the other party's offer and continue negotiating in the following period.

In each period, worker and firm bargain over the real average wage to be paid in that period. If no wage agreement is reached, then no production takes place in that period. It is assumed that the worker enjoys the payoff $b$ while the firm incurs the fixed $\operatorname{cost} \gamma$. The wage bargaining resumes at the beginning of the next period. We follow Snower and Merkl (2006), Jimeno and Thomas (2013), and Balleer et al. (2015) by assuming that disagreement in the current period does not affect future returns. Those

9. It is worth stressing here that (9) is not a differential equation in the function $w_{i t}($.$) . In order to have a$ differential equation, one would have to express $m c_{i t} A_{t} h_{i t}^{\alpha-1}$ in terms of $\omega_{i t}=w_{i t}+w_{i t}^{\prime}\left(h_{i t}\right) h_{i t}$. However, the term $m c_{i t} A_{t} h_{i t}^{\alpha-1}$ reflects the fact that if a given worker $z$ walked away from her job, the demand-constrained firm $i$ would have to make up for the lost output by readjusting the hours of the other workers in the firm. As worker $z$ would no longer be in firm $i$, the first-order condition $m c_{i t} \alpha A_{t} h_{i t}^{\alpha-1}=\omega_{i t}$ for that worker would no longer apply. It would therefore be incorrect to replace $m c_{i t} A_{t} h_{i t}^{\alpha-1}$ by $\frac{\omega_{i t}}{\alpha}$ in equation (9). Thus, by the time the worker and the firm negotiate the wage at the end of period $t$ (when pricing, hiring, and production decisions have already been made), the marginal cost no longer depends on worker $z$ 's marginal wage, and then on her working hours. I would like to thank Carlos Thomas for showing me that $m c_{i t}$ is independent from $h_{i t}$ at the time of the wage bargaining, exactly as in Thomas (2011). 
papers define the disagreement value for a given worker matched with firm $i$ by

$$
\widetilde{W}_{i t}=b+E_{t} \beta_{t, t+1}\left[(1-s) W_{i t+1}+s U_{t+1}\right]
$$

while the disagreement value ${ }^{10}$ for firm $i$ matched with a given worker is defined by

$$
\widetilde{J}_{i t}=-\gamma+E_{t} \beta_{t, t+1}\left[(1-s) J_{i t+1}+s V_{i t+1}\right] .
$$

When the threat points are given by the disagreement values, the surplus of the worker is

$$
W_{i t}-\widetilde{W}_{i t}=w_{i t} h_{i t}-x_{h} \frac{h_{i t}^{1+\eta}}{(1+\eta) u^{\prime}\left(c_{t}\right)}-b
$$

while the surplus of the firm is

$$
J_{i t}-\widetilde{J}_{i t}=m c_{i t} A_{t} h_{i t}^{\alpha}-w_{i t} h_{i t}+\gamma .
$$

The real average wage is still assumed to be determined by the Generalized Nash Solution. ${ }^{11}$ The equilibrium wage therefore satisfies the following surplus-sharing rule:

$$
(1-\zeta)\left(W_{i t}-\widetilde{W}_{i t}\right)=\zeta\left(J_{i t}-\tilde{J}_{i t}\right)
$$

This yields the following real average wage in firm $i$ :

$$
w_{i t}^{c b}=\zeta\left[m c_{i t} A_{t} h_{i t}^{\alpha-1}+\frac{\gamma}{h_{i t}}\right]+(1-\zeta)\left[\frac{b}{h_{i t}}+x_{h} \frac{h_{i t}^{\eta}}{(1+\eta) u^{\prime}\left(c_{t}\right)}\right] .
$$

The real marginal wage in this firm is

$$
\omega_{i t}^{c b}=w_{i t}^{c b}+w_{i t}^{c b^{\prime}}\left(h_{i t}\right) h_{i t}=\zeta m c_{i t} \alpha A_{t} h_{i t}^{\alpha-1}+(1-\zeta) x_{h} \frac{h_{i t}^{\eta}}{u^{\prime}\left(c_{t}\right)} .
$$

Using equation (8), the real marginal wage can be rewritten as

$$
\omega_{i t}^{c b}=x_{h} \frac{h_{i t}^{\eta}}{u^{\prime}\left(c_{t}\right)} .
$$

10. Jung and Kuester (2011), Faia, Lechthaler, and Merkl (2014), and Kaplan and Menzio (2015) implicitly use the same definition for the disagreement values. In these papers, surpluses are directly expressed in flows. This means, for a negotiating party, that the value of a match and the threat point have the same continuation value terms that cancel each other out when writing the surplus. This happens when the threat points are the disagreement values defined by $\widetilde{W}_{i t}$ and $\widetilde{J}_{i t}$. In the words of Kaplan and Menzio (2015), "The assumption that, in case of disagreement, the firm and the worker do not lose contact with each other simplifies the analysis by making the wage only a function of current variables."

11. Boitier and Lepetit (2016) provide an alternative, albeit more complicated, solution for the average wage under credible bargaining. 
The real marginal wage for the credible bargaining is equal to the worker's marginal rate of substitution between consumption and leisure. Hence, the credible bargaining and the Nash bargaining share the same expression for the marginal wage. However, the average wage under credible bargaining is less "flexible" than the average wage under Nash bargaining. Indeed, the average wage for the credible bargaining is insulated from labor-market conditions: contrary to equation (9), neither unemployment nor vacancies appear in equation (11). The average wage resulting from the credible bargaining is therefore sticky with respect to labor-market fluctuations, which notably reflects that the disagreement values are independent from current period variables.

\section{Wage norm}

In order to introduce real wage rigidities, most of the literature that merges NK and search and matching models assumes that the real average wage is set as a weighted average of the Nash bargaining real average wage and a real "wage norm." 12 This norm can take many forms but the last period's average wage or a constant average wage are usually considered. Here a constant wage (equal to the steady-state average wage) is retained as a norm. The real average wage for a given worker in firm $i$ is therefore:

$$
\begin{aligned}
w_{i t}^{w n} & =\psi \bar{w}+(1-\psi) w_{i t}^{n b} \\
& =\psi \bar{w}+(1-\psi)\left[\zeta\left[m c_{i t} A_{t} h_{i t}^{\alpha-1}+\chi \frac{\theta_{t}}{h_{i t}}\right]+(1-\zeta)\left[\frac{b}{h_{i t}}+x_{h} \frac{h_{i t}^{\eta}}{(1+\eta) u^{\prime}\left(c_{t}\right)}\right]\right],
\end{aligned}
$$

where $\psi \in[0,1]$ measures the degree of rigidity of the real average wage. The real marginal wage in this firm is

$$
\omega_{i t}^{w n}=w_{i t}^{w n}+w_{i t}^{w n^{\prime}}\left(h_{i t}\right) h_{i t}=\psi \bar{w}+(1-\psi)\left[\zeta m c_{i t} \psi A_{t} h_{i t}^{\psi-1}+(1-\zeta) x_{h} \frac{h_{i t}^{\eta}}{u^{\prime}\left(c_{t}\right)}\right] .
$$

Using equation (8), the real marginal wage can be rewritten as

$$
\omega_{i t}^{w n}=\frac{\psi \bar{w}+(1-\psi)(1-\zeta) x_{h} \frac{h_{i t}^{\eta}}{u^{\prime}\left(c_{t}\right)}}{1-(1-\psi) \zeta} .
$$

The real marginal wage for this specification is a weighted average of the worker's marginal rate of substitution between consumption and leisure and the constant wage norm. With $\psi=0$, the marginal wage corresponds to the marginal wage under Nash bargaining and credible bargaining. With $\psi=1$, the marginal wage is fixed and equal

12. The wage norm was initiated by Hall (2005) in the search and matching literature. Blanchard and Galí (2007, 2010), Krause and Lubik (2007), Faia (2008), Sveen and Weinke (2008), Christoffel and Linzert (2010), Ravenna and Walsh (2012), among others, take some form of this approach when they integrate real wage rigidities into the NK model. 
to the steady-state average wage. Moreover, an increase in $\psi$ will reduce the responses of both the marginal and average wages.

Vacancy posting. The standard job creation condition is obtained by merging equations (6) and (7). Moreover, replacing $m c_{i t}$ by its expression given by equation (8), we have:

$$
\frac{\chi}{q\left(\theta_{t}\right)}=E_{t} \beta_{t, t+1}\left[\Omega_{i t+1}+(1-s) \frac{\chi}{q\left(\theta_{t+1}\right)}\right]
$$

with

$$
\Omega_{i t}=-\frac{\partial w_{i t} h_{i t} n_{i t}}{\partial n_{i t}}=\left(\frac{\omega_{i t}}{\alpha}-w_{i t}\right) h_{i t}
$$

A firm posts vacancies until the cost of hiring an additional worker equals the expected discounted future benefits from this worker. The costs of hiring a worker are given by the vacancy posting costs, $\chi$, multiplied by the average duration of a vacancy, $\frac{1}{q\left(\theta_{t}\right)}$. The benefits of hiring an additional worker are his shadow value, $\Omega_{i t}$, plus the vacancy posting costs saved in case the employment relationship continues.

The shadow value of an additional worker, $\Omega_{i t}$, captures the reduction in the wage bill induced by an additional hire. Indeed, hiring an additional worker allows the firm to reduce future hours worked of all the firm's employees by shifting production from the intensive to the extensive margin. Most importantly for our purpose, $\Omega_{i t}$ depends on the gap between the marginal wage and the average wage, $\left(\frac{\omega_{i t}}{\alpha}-w_{i t}\right)$. The intuition is simple: each of the hours worked by an additional worker will be paid at the average wage; if the firm did not hire this worker, each of these hours would be paid at the marginal wage. The "wage gap" thus measures the savings realized on each hour.

Price setting and inflation dynamics. From equations (8), (10), (12), and (14), the real marginal cost for each wage specification is

$$
\begin{aligned}
m c_{i t}^{n b} & =m c_{i t}^{c b}=x_{h} \frac{h_{i t}^{\eta}}{u^{\prime}\left(c_{t}\right) m p h_{t}} \\
m c_{i t}^{w n} & =\frac{\psi \bar{w}+(1-\psi)(1-\zeta) x_{h} \frac{h_{i t}^{\eta}}{u^{\prime}\left(c_{t}\right)}}{(1-(1-\alpha) \zeta) m p h_{t}} .
\end{aligned}
$$

Two results are worth noting. First, the Nash bargaining and the credible bargaining generate the same real marginal cost. This stems from the same real marginal wage displayed by both wage bargains. The real marginal cost is given by the ratio between the marginal rate of substitution between consumption and leisure and the marginal product of hours. Second, since $\psi \in[0,1], m c_{i t}^{w n}$ is less flexible with respect to hours per worker than $m c_{i t}^{n b}$ and $m c_{i t}^{c b}$. 
Firms reset their price in a Calvo (1983) fashion. Each period, a firm has a $(1-\delta)$ probability of re-optimizing its price and a $\delta$ probability of keeping its price of the last period:

$$
P_{i t}= \begin{cases}P_{i t}^{*} & \text { with probability } 1-\delta \\ P_{i t-1} & \text { with probability } \delta .\end{cases}
$$

When a firm has the chance to reset its price, it chooses $P_{i t}$ so as to maximize its value $\Pi_{i t}$, subject to constraint (18). The first-order condition is

$$
\partial P_{i t}: \quad E_{t} \sum_{T=t}^{\infty} \delta^{T-t} \beta_{t, T} P_{T}^{\varepsilon} y_{T}^{d}\left\{\frac{P_{i t}^{*}}{P_{T}}-\frac{\varepsilon}{\varepsilon-1} m c_{i T(\mid t}\right\}=0,
$$

where $P_{i t}^{*}$ is the pricing decision, while the subscript $T \mid t$ denotes period $T$ values conditional on the firm not having reset its price since period $t$. According to equation (20), price setters target a constant mark-up $\frac{\epsilon}{\epsilon-1} \succ 1$ over real marginal costs for the expected duration of the price set in period $t$.

In a technical appendix, ${ }^{13}$ we show that the marginal cost schedules (16) and (17) imply different slopes for the New Keynesian Phillips Curve (NKPC). Since the Nash bargaining and the credible bargaining generate the same real marginal cost expression, we focus our attention on the Nash bargaining on the one hand, and the wage norm on the other. The results for the Nash bargaining, in this subsection, therefore convey to the credible bargaining. The NKPC for the Nash bargaining and the wage norm are given by

$$
\begin{aligned}
& \pi_{t}^{n b}=\beta E_{t} \pi_{t+1}+\kappa^{n b} \widehat{m c}_{t}^{n b}, \\
& \pi_{t}^{w n}=\beta E_{t} \pi_{t+1}+\kappa^{w n} \widehat{m c}_{t}^{w n},
\end{aligned}
$$

where $\pi_{t} \equiv \log \left(\frac{P_{t}}{P_{t 1}}\right)$ is the inflation rate and "hats" denote log deviations of a variable around its steady-state value. $\kappa^{n b}$ and $\kappa^{w n}$ read as follows:

$$
\begin{aligned}
\kappa^{n b} & =\frac{(1-\delta \beta)(1-\delta)}{\delta} \frac{1}{1+\phi^{n b}}, \\
\kappa^{w n} & =\frac{(1-\delta \beta)(1-\delta)}{\delta} \frac{1}{1+\phi^{w n}} .
\end{aligned}
$$

The expressions for $\kappa^{n b}$ and $\kappa^{w n}$ are very similar to the one produced either by an NK model without search frictions (e.g., Galí 2008, chapter 3), or by a NK model with search frictions in which the firms setting prices are different from the firms that

13. Available upon request to the author. 
are subject to search frictions (e.g., Walsh 2005). The only difference is the presence of the $\phi^{n b}$ and $\phi^{w n}$ terms, resulting from the fact that there is a single set of firms that both set prices and hire workers in a frictional labor market: ${ }^{14}$

$$
\begin{aligned}
\phi^{n b} & =\frac{1}{\alpha}\left[\eta \epsilon-\delta \beta \eta \tau_{n b}^{n}\right], \\
\phi^{w n} & =\frac{1}{\alpha}\left[D \eta \epsilon-D \delta \beta \eta \tau_{w n}^{n}\right],
\end{aligned}
$$

with $\epsilon$ the elasticity of substitution between differentiated goods. The expressions (and the derivation) for $\tau_{n b}^{n}$ and $\tau_{w n}^{n}$ are provided in the technical appendix. The parameter $D$ is given by

$$
D=\frac{(1-\psi)(1-\zeta) x_{h} \frac{h^{\eta}}{u^{\prime}(c)}}{\psi \bar{w}+(1-\psi)(1-\zeta) x_{h} \frac{h^{\eta}}{u^{\prime}(c)}} \leq 1 .
$$

The parameters $\phi^{n b}$ and $\phi^{w n}$ have two components each: $\eta \epsilon$ and $\delta \beta \eta \tau^{n b}$ for $\phi^{n b}$; $D \eta \epsilon$ and $D \delta \beta \eta \tau^{w n}$ for $\phi^{w n} .{ }^{15}$ The terms $\eta \epsilon$ and $D \eta \epsilon$ embody the existence of strategic complementarities in price setting, or real price rigidities in Ball and Romer (1990) terminology. These complementarities dampen the price level adjustment in response to real marginal cost movements. To understand this point, take a price-setter that is considering a reduction in its nominal price. Given the prices of other firms, such a reduction implies a reduction in its real price. This increases its sales by an elasticity $\epsilon$. Since employment is predetermined, the firm has to increase hours per worker in the initial period so as to accommodate the higher demand for its good. The rise in hours entails an increase in the real marginal cost, that is, the cost of a marginal hour per employee, which is all the more important as $\eta$ is large. This anticipated increase in real marginal costs leads the firm to choose a smaller price reduction than the one initially considered. This results in strategic complementarities: given that some prices are kept unchanged (due to Calvo price setting), the firms that have the ability to adjust theirs, change these prices by a little amount.

Crucially, as $D \leq 1$, the degree of strategic complementarities is higher for the Nash bargaining than for the wage norm. Indeed, for the Nash bargaining, an additional hour per worker increases the real marginal cost by an elasticity $\eta$, through the

14. Thomas (2011) raises the analogy between the present model and those, exemplified by Woodford (2005), with firm-specific capital. Indeed, the search frictions characterizing the labor market give rise (endogenously) to long-run employment relationships, thus making labor specific to each firm. Hence, the employment stock plays an analogous role to the capital stock in firm-specific capital models. Thomas stresses that this implies similar complications in firms' price-setting decisions, because the latter interact with forward-looking hiring decisions (investment decisions in firm-specific capital models). In particular, the relative stock of workers of a given firm now appears in its pricing decision. In order to solve the resulting difficulty, Thomas (2011, pp. 1142-1144) applies the method developed by Woodford (2005) in the context of a model with firm-specific capital. We follow Thomas (and therefore Woodford) in our technical appendix.

15. The following discussion closely follows Thomas (2011, pp. 1145-1146). 
increase in workers' marginal disutility of labor. However, for the wage norm, only a fraction $D$ of the real marginal cost is flexible. An additional hour per worker thus increases the real marginal cost only by an elasticity $D \eta$.

The terms $\delta \beta \eta \tau^{n b}$ and $D \delta \beta \eta \tau^{w n}$ reflect that real marginal costs, for a given amount of output, decrease with the firms' employment stock. Contrary to strategic complementarities, this accelerates price adjustment to real marginal cost fluctuations. ${ }^{16}$ Thomas (2011) demonstrates that $\eta \epsilon>\delta \beta \eta \tau^{n b}$ while we show in the technical appendix that $D \eta \epsilon>D \delta \beta \eta \tau^{w n}$. This means that the latter effect is dominated by the strategic complementarities effect, for both the Nash bargaining and the wage norm. Both $\phi^{n b}$ and $\phi^{w n}$ are therefore positive. Furthermore, we also show that $\phi^{n b} \geq \phi^{w n}$. This implies that the NKPC resulting from the Nash bargaining is flatter than the NKPC resulting from the wage norm: for the Nash bargaining, fluctuations in real marginal costs are turned into inflation by a lower extent. This is due to the higher degree of strategic complementarities in price setting stemming from this wage bargain.

\subsection{Aggregate Output and Market Clearing}

Aggregate output $y_{t}$ is obtained by aggregating the goods produced by each firm:

$$
y_{t} \equiv\left(\int_{0}^{1} y_{i t}^{\frac{\epsilon-1}{\epsilon}} d i\right)^{\frac{\epsilon}{\epsilon-1}} .
$$

The goods market clearing condition is

$$
y_{t}=y_{t}^{d},
$$

which implies

$$
y_{t}=c_{t}+\chi v_{t} .
$$

From the firm's production function, we obtain the aggregate production function:

$$
y_{t}=A_{t} n_{t} h_{t}^{\alpha} .
$$

16. To make things clear, take the same firm considering a reduction in its nominal price. With such a reduction, the firm expects a larger employment stock, and therefore lower real marginal costs in the future. This effect leads the firm to choose a larger price reduction than the one initially considered. Again, this effect is stronger for the Nash bargaining: as the real marginal cost is more flexible for the Nash bargaining, the anticipation of even lower real marginal costs in the future leads the firm to reduce its price even more. 


\subsection{Monetary Policy}

We follow much of the NK literature by assuming that monetary policy is described by a Taylor-type interest rate rule:

$$
i_{t}=\rho_{i} i_{t-1}+\left(1-\rho_{i}\right)\left(\rho+\varphi_{\pi} \pi_{t}+\varphi_{y} \widehat{y}_{t}\right)+e_{t}^{m},
$$

where $\rho \equiv-\log \beta$ denotes the household's discount rate, $\rho_{i}$ captures the degree of interest rate smoothing, $\varphi_{\pi}$ and $\varphi_{y}$ the responses to inflation and deviations of output from its steady-state value, respectively, and $e_{t}^{m}$ is an i.i.d. shock to monetary policy.

\subsection{Log-Linearized Equilibrium Conditions}

From now on, we assume the following functional forms for the preferences regarding consumption and the matching technology:

$$
\begin{aligned}
& u\left(c_{t}\right)=\ln \left(c_{t}\right), \\
& m\left(u_{t}, v_{t}\right)=m_{0} u_{t}^{1-\varsigma} v_{t}^{\varsigma} .
\end{aligned}
$$

The equilibrium of the model is characterized by the AR(1) process for labor productivity, by equation (24), and by the following equations: $:^{17}$

Tightness:

$$
\widehat{\theta_{t}}=\widehat{v}_{t}-\widehat{u}_{t} .
$$

Employment law of motion:

$$
\widehat{n}_{t+1}=(1-s) \widehat{n}_{t}+s\left(\varsigma \widehat{v}_{t}+(1-\varsigma) \widehat{u}_{t}\right) .
$$

Unemployment:

$$
\widehat{u}_{t}=-\frac{n}{u} \widehat{n}_{t} .
$$

Euler equation:

$$
\left.\widehat{c_{t}}=E_{t} \widehat{c_{t+1}}-\widehat{\left(i_{t}\right.}-E_{t} \pi_{t+1}\right) \text {. }
$$

Job creation condition:

$$
\frac{\chi}{q(\theta)}(1-\varsigma) \widehat{\theta}_{t}=h \beta E_{t}\left(\frac{\omega}{\alpha} \widehat{\omega}_{t+1}-w \widehat{w}_{t+1}\right)
$$

17. Attention is restricted to a log-linear approximation to the equilibrium dynamics around a zeroinflation steady state. The steady-state value of a given variable is represented by this variable without time subscript, while "hats" still denote log-deviations of a variable around its steady-state value. 


$$
\left.+\left(\frac{\omega}{\alpha}-w\right) h \beta E_{t} \widehat{h}_{t+1}+\widehat{c}_{t}-\widehat{c}_{t+1}\right)+(1-s) \frac{\chi}{q(\theta)} \beta E_{t}\left((1-\varsigma) \widehat{\theta}_{t+1}+\widehat{c}_{t}-\widehat{c}_{t+1}\right) .
$$

Real average wages:

$$
\begin{aligned}
\widehat{w}_{t}^{n b}= & \frac{1}{w}\left[\zeta m c A h^{\alpha-1}\left(\widehat{m c}_{t}+\widehat{A}_{t}+(\alpha-1) \widehat{h}_{t}\right)+\frac{\zeta \chi \theta}{h}\left(\widehat{\theta}_{t}-\widehat{h}_{t}\right)-\frac{(1-\zeta) b}{h} \widehat{h}_{t}\right. \\
& \left.+(1-\zeta) x_{h} \frac{h^{\eta} c}{1+\eta}\left(\eta \widehat{h}_{t}+\widehat{c}_{t}\right)\right] \\
\widehat{w}_{t}^{c b}= & \frac{1}{w}\left[\zeta m c A h^{\alpha-1}\left(\widehat{m c}_{t}+\widehat{A}_{t}+(\alpha-1) \widehat{h}_{t}\right)-\frac{\zeta \gamma}{h} \widehat{h}_{t}-\frac{(1-\zeta) b \widehat{h}_{t}}{h}\right. \\
& \left.+(1-\zeta) x_{h} \frac{h^{\eta} c}{1+\eta}\left(\eta \widehat{h}_{t}+\widehat{c}_{t}\right)\right] \\
\widehat{w}_{t}^{w n}= & \frac{(1-\psi)}{w}\left[\zeta m c A h^{\alpha-1}\left(\widehat{m c}_{t}+\widehat{A}_{t}+(\alpha-1) \widehat{h}_{t}\right)+\frac{\zeta \chi \theta}{h}\left(\widehat{\theta}_{t}-\widehat{h}_{t}\right)-\frac{(1-\zeta) b \widehat{h}_{t}}{h}\right. \\
& \left.+(1-\zeta) x_{h} \frac{h^{\eta} c}{1+\eta}\left(\eta \widehat{h}_{t}+\widehat{c}_{t}\right)\right]
\end{aligned}
$$

Real marginal wages:

$$
\begin{aligned}
& \widehat{\omega}_{t}^{c b}=\widehat{\omega}_{t}^{n b}=\eta \widehat{h}_{t}+\widehat{c}_{t} \\
& \widehat{\omega}_{t}^{w n}=\frac{1}{\omega}\left[\frac{(1-\psi)(1-\zeta)}{1-(1-\alpha) \zeta} x_{h} h^{\eta} c\left(\eta \widehat{h}_{t}+\widehat{c}_{t}\right)\right] .
\end{aligned}
$$

Marginal product of hours:

$$
\widehat{m p h}_{t}=\widehat{A}_{t}+(\alpha-1) \widehat{h}_{t} \text {. }
$$

Real marginal costs:

$$
\begin{aligned}
& \widehat{m c}_{t}^{c b}=\widehat{m c}_{t}^{n b}=\eta \widehat{h}_{t}+\widehat{c}_{t}-\widehat{m p h}_{t} \\
& \widehat{m c}_{t}^{w n}=\frac{1}{m c}\left[\frac{(1-\psi)(1-\zeta)}{(1-(1-\alpha) \zeta) m p h} x_{h} h^{\eta} c\left(\eta \widehat{h}_{t}+\widehat{c}_{t}\right)\right]-\widehat{m p h}_{t} .
\end{aligned}
$$


NKPC:

$$
\begin{aligned}
& \pi_{t}^{c b}=\pi_{t}^{n b}=\beta E_{t} \pi_{t+1}+\kappa^{n b} \widehat{m c}_{t}^{n b} \\
& \pi_{t}^{w n}=\beta E_{t} \pi_{t+1}+\kappa^{w n} \widehat{m c}_{t}^{w n} .
\end{aligned}
$$

Final goods market clearing condition:

$$
\widehat{y_{t}}=\frac{c}{y} \widehat{c_{t}}+\frac{\chi v}{y} \widehat{v}_{t}
$$

Aggregate production function:

$$
\widehat{y_{t}}=\widehat{A}_{t}+\widehat{n}_{t}+\alpha \widehat{h}_{t} .
$$

\section{THE JOINT DYNAMICS OF UNEMPLOYMENT AND INFLATION}

\subsection{Calibration}

Technology, preferences, and price rigidities. Time is measured in months. We set $\alpha=0.99$, implying only mildly decreasing returns to hours worked per worker. We select a standard value for the discount factor $\beta=0.99^{1 / 3}$, corresponding to an annual interest rate equal of $4 \%$. Hours per worker are normalized to one at the steady state and the scaling parameter $x_{h}$ is adjusted accordingly. We set $\eta=2$, corresponding to a Frisch labor-supply elasticity $(1 / \eta)$ of 0.5 . We choose a standard average duration for a price contract of approximately a year, which entails $\delta=1-\frac{1}{12}$. The monopolistic markup is set to a conventional level of $20 \%$, implying an elasticity of substitution between differentiated goods $\epsilon$ equal to 6 . Given the values of $\alpha, \beta, \eta, \epsilon$, and $\delta$, we obtain $\phi^{n b}=1.55$ and then $\kappa^{n b}=0.0028$ for both the Nash bargaining and the credible bargaining. At the same time, we have $\phi^{w n}=0.72$ and $\kappa^{w n}=0.0042$ for the wage norm. Therefore, the slope of the NKPC for the Nash bargaining and the credible bargaining is flatter than the slope of the NKPC for the wage norm.

Labor market. From Shimer (2005), we set the separation rate $s$ at 0.03 . We target a steady-state unemployment rate of 0.06 (which is the average rate of our sample) and a probability of finding a worker of 0.33 (which corresponds to the quarterly probability of 0.70 found by Den Haan, Ramey, and Watson 2000). The efficiency parameter of the matching function $m_{0}$ is set to match these two targets. For the elasticity of the matching function with respect to vacancies, we select $\varsigma=0.6$, from the evidence reported in Blanchard and Diamond (1989). In accordance with the figure found by Silva and Toledo (2009), the value of the vacancy posting cost $\chi$ is chosen so as to represents $10 \%$ of the monthly real wage income at the steady state, which entails $\chi=0.082$. We let $b$ adjusts to solve the job-creation condition at the steady state. We obtain $b=0.425$, which is very close to the value of 0.4 often used in the 
TABLE 1

PARAMETERS

\begin{tabular}{llc}
\hline \hline Parameter & \multicolumn{1}{c}{ Definition } & Value \\
\hline$\beta$ & Discount factor & $0.99^{1 / 3}$ \\
$\eta$ & Convexity of labor disutility & 2 \\
$x_{h}$ & Scaling factor to disutility of work & 0.884 \\
$\delta$ & Fraction of unchanged prices & 0.92 \\
$\epsilon$ & Elasticity of demand curves & 6 \\
$\kappa^{n b}$ & Slope NKPC, Nash bargaining & 0.0028 \\
$\kappa^{w n}$ & Slope NKPC, wage norm & 0.0042 \\
$s$ & Separation rate & 0.03 \\
$\zeta$ & Elasticity matching fct wrt vacancies & 0.6 \\
$m_{o}$ & Efficiency parameter of the matching fct & 0.38 \\
$\chi$ & Vacancy posting cost & 0.082 \\
$\zeta$ & Worker's bargaining power & 0.5 \\
$b$ & Flow value of unemployment & 0.425 \\
$\gamma$ & Fixed cost for employers, credible bargaining & 0.117 \\
$\psi$ & Partial adjustment coefficient, wage norm & 0.4 \\
$\rho_{a}$ & AC of productivity shock & $0.95^{1 / 3}$ \\
$\varphi_{\pi}$ & Response to inflation in the Taylor rule & 1.5 \\
$\varphi_{y}$ & Response to output gap in the Taylor rule & $0.5 / 12$ \\
$\rho_{i}$ & Interest rate smoothing & $0.8^{1 / 3}$ \\
\hline
\end{tabular}

literature. The worker's bargaining power $\zeta$ is chosen at 0.5 , a common practice that implies a symmetric bargaining. The value of the fixed cost incurred by employers under credible bargaining, $\gamma=0.117$, is chosen so as to induce the same steady-state average wage as we get for the Nash bargaining. ${ }^{18}$ Finally, the partial adjustment coefficient $\psi$ of the wage norm is set to 0.4 , the value that allows to reproduce the empirical volatility of the real average wage. Note that at the steady state, the average wage for the wage norm is always equal to the average wage for the Nash bargaining, whatever the value of $\psi$. Overall, our calibration strategy implies the same steadystate values for all the wage bargains considered.

Monetary policy and shocks. We set standard values for the parameters of the Taylor rule: $\varphi_{\pi}=1.5, \varphi_{y}=0.5 / 12$, and $\rho_{i}=0.8^{1 / 3}$. We select the standard deviation of the interest rate shock, $\sigma_{m}=0.058 \%$, from Walsh (2005). ${ }^{19}$ The aggregate productivity shock $A_{t}$ is normalized to one at the steady state. The log of this shock follows an $\mathrm{AR}(1)$ process with an auto-correlation coefficient $\rho_{a}$ set at the usual value of $0.95^{1 / 3}$. The standard deviation of the productivity shock, for each wage bargain, is chosen to replicate the standard deviation of real output in the data.

All the parameters are summarized in Table 1 while the steady state for some of the model variables is reported in Table 2.

18. This value for $\gamma$ is in fact equal to $\chi \theta$, as at the steady state the average wage for the credible bargaining is equal to the average wage for the Nash bargaining only if $\gamma=\chi \theta$.

19. Walsh (2005) finds a quarterly standard deviation for this shock equal to $0.2 \%$, — corresponding to a monthly value of $0.058 \%$. 
TABLE 2

STEADY STATE

\begin{tabular}{llc}
\hline \hline Variable & \multicolumn{1}{c}{ Definition } & Value \\
\hline$y$ & Real output & 0.94 \\
$c$ & Consumption & 0.933 \\
$h$ & Hours per worker & 1 \\
$n$ & Employment & 0.94 \\
$u$ & Unemployment rate & 0.06 \\
$v$ & Vacancy rate & 0.085 \\
$w$ & Real average wage & 0.825 \\
$\omega$ & Real marginal wage & $1 / 1.2$ \\
$m c$ & Real marginal cost & $1 / 1.2$ \\
\hline
\end{tabular}

TABLE 3

LABOR-MARKET AND INFLATION DYNAMICS

\begin{tabular}{|c|c|c|c|c|c|c|c|c|c|c|}
\hline & \multicolumn{5}{|c|}{$\mathrm{CB}$} & \multicolumn{3}{|c|}{ NB } & \multicolumn{2}{|c|}{ WN } \\
\hline & Data & Prod. & Mon. & Both & Prod. & Mon. & Both & Prod. & Mon. & Both \\
\hline$\sigma\left(y_{t}\right), \%$ & 1.56 & 1.25 & 0.92 & 1.56 & 1.34 & 0.85 & 1.58 & 1.30 & 0.88 & 1.56 \\
\hline$\sigma\left(u_{t}\right) / \sigma\left(y_{t}\right)$ & 8.48 & 6.90 & 10.86 & 8.46 & 3.73 & 5.35 & 4.28 & 2.98 & 4.94 & 3.72 \\
\hline$\sigma\left(v_{t}\right) / \sigma\left(y_{t}\right)$ & 9.11 & 7.76 & 13.20 & 9.95 & 4.62 & 6.57 & 5.29 & 3.11 & 5.94 & 4.23 \\
\hline$\sigma\left(\theta_{t}\right) / \sigma\left(y_{t}\right)$ & 17.22 & 13.04 & 20.90 & 16.16 & 7.22 & 10.33 & 8.29 & 5.55 & 9.49 & 7.04 \\
\hline$\sigma\left(h_{t}\right) / \sigma\left(y_{t}\right)$ & 0.34 & 0.65 & 0.54 & 0.61 & 0.85 & 0.73 & 0.83 & 0.59 & 0.75 & 0.65 \\
\hline$\sigma\left(w_{t}\right) / \sigma\left(y_{t}\right)$ & 0.60 & 0.66 & 1.08 & 0.83 & 1.32 & 2.11 & 1.60 & 0.48 & 0.82 & 0.61 \\
\hline$\epsilon\left(\omega_{t}\right)$ & {$[1.84-3.24]$} & 1.79 & 3.43 & 2.34 & 1.84 & 3.29 & 2.25 & 1.01 & 1.38 & 1.17 \\
\hline$\sigma\left(\pi_{t}\right) / \sigma\left(y_{t}\right)$ & 0.18 & 0.41 & 0.08 & 0.33 & 0.42 & 0.13 & 0.37 & 0.42 & 0.09 & 0.35 \\
\hline
\end{tabular}

\subsection{Quantitative Analysis}

The second column of Table 3 displays the standard deviations and autocorrelations of the main labor-market variables and inflation. We consider U.S. data from 1953:q1 to 2013:q2. ${ }^{20}$ Two well-known stylized facts are summarized: (i) the unemployment and vacancy rates (second and third rows, respectively) are highly volatile, as compared to real output; (ii) the inflation rate (eighth row) is only weakly volatile, again as compared to real output. ${ }^{21}$

20. All data are taken from the Federal Reserve Bank of St. Louis database, except the vacancy rate that comes from the index built by Barnichon (2010) (available on Barnichon's website). We use quarterly, seasonally adjusted data on real GDP (in billions of chained 2009 dollars), civilian unemployment rates, civilian employment, the composite Help-Wanted Index, hours per employee in the nonfarm business sector, real hourly compensation in the nonfarm business sector, and quarter-on-quarter inflation of the GDP deflator. All data, except inflation, are logged and HP-filtered with a conventional smoothing parameter $(1,600)$

21. In order to calculate model moments, we follow Thomas (2011). We simulate 816 months of artificial data and take quarterly averages. We discard the first 30 observations so as to eliminate the effects of initial conditions. We are therefore left with 242 observations, which corresponds to the sample size. These simulated data are HP-filtered in line with actual data. We next calculate the relevant second moments. We repeat this operation 200 times and finally take averages for each vector of moments. 
The seventh row of Table 3 gives the elasticity of the marginal wage with respect to hours per worker, $\epsilon\left(\omega_{t}\right){ }^{22}$ The empirical values for this elasticity comes from Bils (1987). In a first approach, Bils estimates the effect of hours on overtime hours directly, assuming an overtime premium of $50 \%$. He finds that an increase in hours per week from 40 to 41 in manufacturing ${ }^{23}$ raises $\omega_{t}$ by $4.6 \%$. This implies $\epsilon\left(\omega_{t}\right)=1.84$. In a second approach, the marginal wage schedule is estimated indirectly from observing the cost-minimizing choices made by firms for employment and hours. Using OLS, Bils finds that going from 40 to 41 hours per week raises $\omega_{t}$ by $6.6 \%$, which implies $\epsilon\left(\omega_{t}\right)=2.64$. Using instrumental variables, the increase in $\omega_{t}$ is $8.1 \%$, which implies $\epsilon\left(\omega_{t}\right)=3.24 .^{24}$

The model-simulated moments (from the third to the last column) are provided when the source of the fluctuations are productivity shocks ("Prod."), monetary policy shocks ("Mon.") and both types of shocks together.

Labor-market dynamics. Table 3 makes clear that the credible bargaining (CB) replicates the high volatility of the unemployment and vacancy rates. Conversely, the Nash bargaining $(\mathrm{NB})$ and the wage norm $(\mathrm{WN})$ generate only small fluctuations for these two rates.

In order to illustrate how the relative movements of the marginal and average wages are critical in producing these results, let us assume that the economy is hit by an expansionary monetary policy shock. Figure 2 displays the dynamic effects of a decrease of 25 basis points in $e_{t}^{m} \cdot{ }^{25}$ Since most firms cannot reset their selling price instantaneously, they respond to the resulting rise in aggregate demand by expanding production. Given that employment is predetermined, these firms have to hire additional hours of existing employees to raise production when the shock occurs. The immediate increase in hours per worker is roughly the same for the three wage bargains considered. However, this increase leads to differentiated responses for the marginal wage. This wage rises significantly under credible bargaining and Nash bargaining, while it increases only moderately for the wage norm. At the same time, firms create jobs that will become productive in the following period. The labor market therefore tightens, which pushes up the average wage. Again, the responses differ across the wage bargains: the average wage rises substantially under Nash bargaining, while it increases only mildly for the wage norm and the credible bargaining. ${ }^{26}$ According to equation (15), job creations are driven by the gap between the marginal wage and the average wage. This wage gap hardly increases for the

22. For the simulated model, this elasticity is approximated by $\frac{\sigma\left(\omega_{t}\right)}{\sigma\left(h_{t}\right)}$.

23. For the 21 SIC classified two-digit manufacturing industries from 1956 to 1983 . We are not aware of newer attempts to measure the shape of the marginal wage.

24. It is worthy to note that, while $\epsilon\left(\omega_{t}\right)$ can take different values, the relation between the marginal wage and the average wage is always given by $\omega_{t}=w_{t}+w_{t}^{\prime}\left(h_{t}\right) h_{t}$, which is exactly the relation that holds in our baseline framework.

25. Corresponding to a decrease of 100 basis points in the annualized nominal rate.

26. Actually, the average wage does not increase at all with labor-market tightness under the particular version of the credible bargaining retained in this paper. This wage nonetheless responds to demand shocks through their impact on hours per worker. 

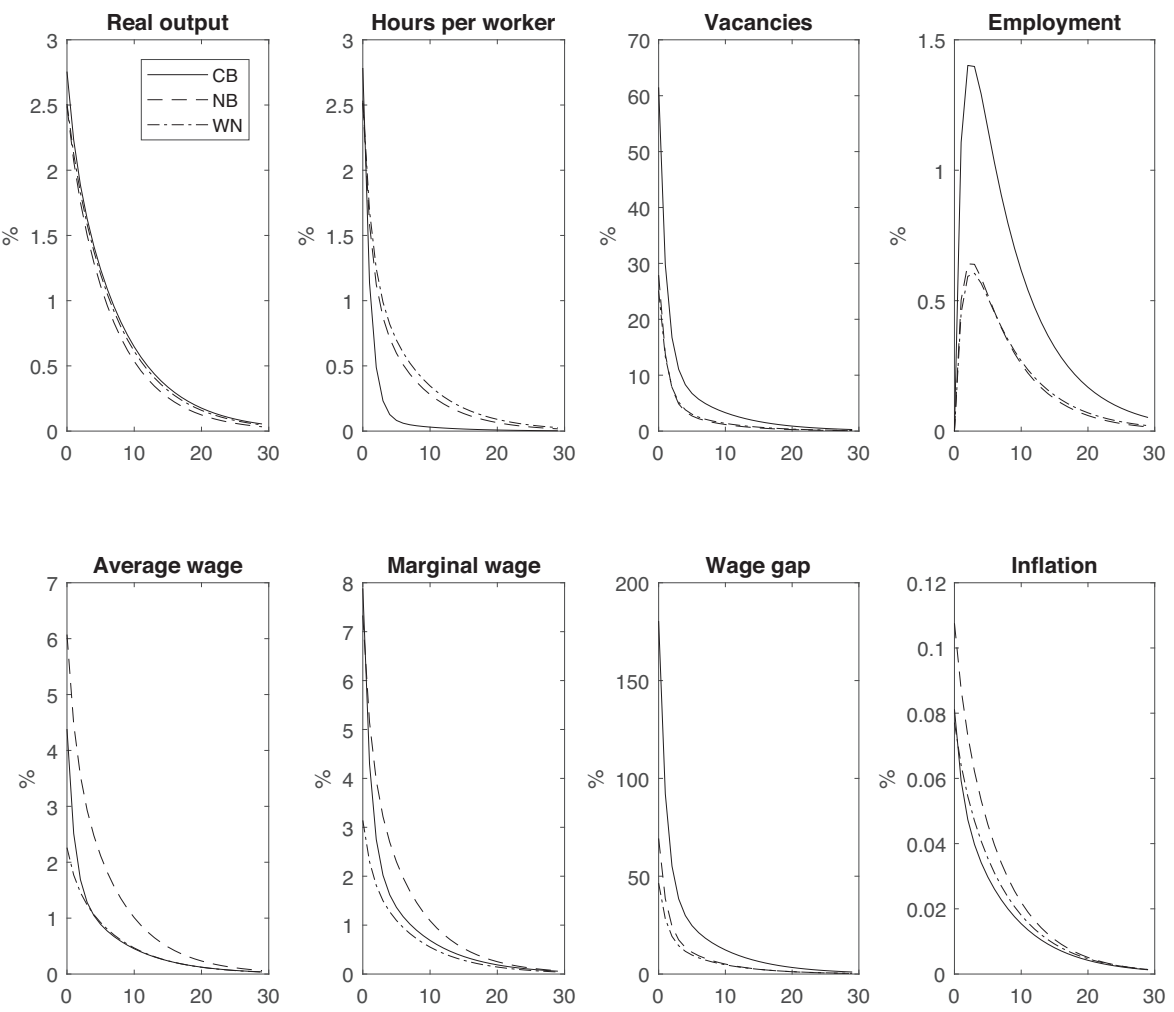

Fig 2. IRF to an Expansionary Monetary Policy Shock.

wage norm and the Nash bargaining as, for each of these bargains, the marginal wage and the average wage display roughly the same pattern. Instead, this gap sharply rises under credible bargaining, given that the marginal wage increases much more than the average wage. Hence, job creations are magnified under this latter wage bargain, explaining the much higher increase in vacancies and, subsequently, in employment.

Similarly, Figure 3 displays the economy's response to a one-standard deviation positive shock to labor productivity. As aggregate demand is initially not affected by this kind of shock, firms keep on producing the same output. A constant output associated with a higher productivity implies that firms now need less labor. Hours per worker thus decline on impact, inducing a fall in the marginal wage that is stronger for the credible bargaining and the Nash bargaining than for the wage norm. Firms also reduce job creations, inducing a fall in the average wage that is stronger for the Nash bargaining than for the credible bargaining and the wage norm. The wage gap therefore collapses under credible bargaining, whereas its decrease is only limited 

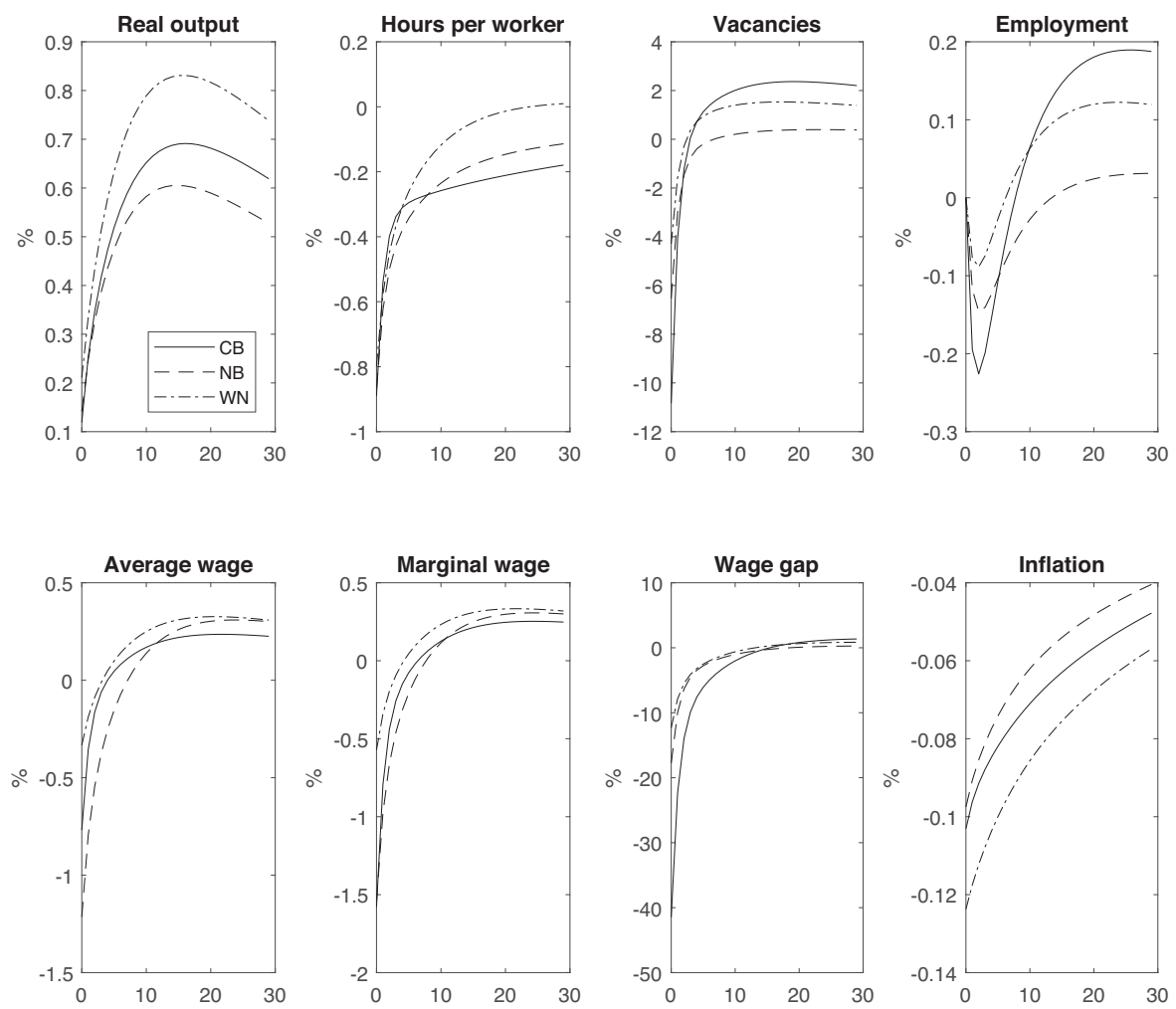

Fig 3. IRF to a Positive Productivity Shock.

for the Nash bargaining and the wage norm. The sharper fall in the wage gap under credible bargaining generates a larger decline in vacancies, and then in employment.

Hence, a NK model for which firms unilaterally adjust both margins of labor is able to replicate the dynamics of unemployment, once is embedded a wage bargain generating larger responses for the marginal wage than for the average wage. Two points are worth emphasizing here. First, other wage bargains than the credible bargaining can reproduce the volatility of the unemployment and vacancy rates, as long as they deliver sufficient variations in the wage gap. In the technical appendix, we notably show that this is the case for the Nash bargaining when the worker's bargaining power is close to zero. ${ }^{27}$ Second, a main conclusion that can be drawn from this subsection is that what matters for labor-market dynamics is not the "stickiness" of wages per se, but the stickiness of the average wage with respect to the marginal wage. To see this even more clearly, the third column of Table 4 provides the results when a very

27. A low value for this parameter reduces the responses of the average wage, while leaving unchanged the responses of the marginal wage. 
TABLE 4

LABOR-MARKET AND INFLATION DYNAMICS

\begin{tabular}{lcccccc}
\hline \hline & Data & $\begin{array}{c}\text { Baseline } \\
\text { WN }(\psi=0.9)\end{array}$ & CB & $\begin{array}{c}\text { RTM } \\
\text { NB }\end{array}$ & WN & CSE \\
\hline$\sigma\left(y_{t}\right), \%$ & 1.56 & 1.56 & 1.56 & 1.55 & 1.56 & 1.57 \\
$\sigma\left(u_{t}\right) / \sigma\left(y_{t}\right)$ & 8.48 & 3.14 & 1.10 & 1.14 & 1.12 & 4.47 \\
$\sigma\left(v_{t}\right) / \sigma\left(y_{t}\right)$ & 9.11 & 3.07 & 1.18 & 1.24 & 1.16 & 5.66 \\
$\sigma\left(\theta_{t}\right) / \sigma\left(y_{t}\right)$ & 17.22 & 5.77 & 2.05 & 2.15 & 2.08 & 9.37 \\
$\sigma\left(h_{t}\right) / \sigma\left(y_{t}\right)$ & 0.34 & 0.64 & 0.93 & 1.08 & 0.75 & 0.78 \\
$\sigma\left(w_{t}\right) / \sigma\left(y_{t}\right)$ & 0.60 & 0.06 & 0.34 & 0.61 & 0.27 & 1.56 \\
$\epsilon\left(\omega_{t}\right)$ & {$[1.84-3.24]$} & 0.17 & 0.37 & 0.58 & 0.36 & 2.24 \\
$\sigma\left(\pi_{t}\right) / \sigma\left(y_{t}\right)$ & 0.18 & 0.32 & 0.33 & 0.34 & 0.33 & 0.36 \\
\hline
\end{tabular}

high value of wage rigidity $\left(\psi=0.9\right.$ ) is chosen for the wage norm. ${ }^{28}$ In this case, both the average wage and the marginal wage exhibit very small variations. But as the average wage is not much stickier than the marginal wage, the volatility of the unemployment and vacancy rates is not amplified.

Inflation dynamics. From the last row of Table 3, we can see that every wage bargain replicates the low volatility of the inflation rate. This was expected for the wage norm, given that this wage bargain delivers small variations in the marginal wage (and therefore in marginal cost). However, the ability of the Nash bargaining and the credible bargaining to generate small movements in the inflation rate is more surprising, as these wage bargains display large variations in the marginal wage.

To understand this result, recall that the variations of the marginal wage alter the dynamics of inflation through two different effects. The first effect is direct: for a given slope of the NKPC, fluctuations in the marginal wage implies fluctuations in marginal cost and therefore inflation movements. Moreover, the magnitude of this effect is positively related to the size of the variations in the marginal wage: the higher these variations, the larger the responses of inflation. At the same time, there is an indirect effect operating through the slope of the NKPC. This second effect is related to the presence of strategic complementarities. Indeed, a firm that considers a fall in its price (e.g., after a positive productivity shock) will have to raise hours per employee to satisfy the resulting additional demand. The increase in the marginal wage that will ensue finally leads this firm to choose a smaller price reduction, which flattens the NKPC. Furthermore, the amount of strategic complementarities positively depends on the size of the fluctuations in the marginal wage: the larger the increase in the marginal wage in response to the rise in hours per worker, the smaller the price reduction finally chosen and the flatter the NKPC.

The seventh row of Table 3 shows that under Nash bargaining and credible bargaining, the marginal wage sharply responds to variations in hours per worker. This entails a large direct effect on inflation dynamics. On the other hand, strong strategic

28. Each column of Table 4 displays results for both monetary and productivity shocks together. 


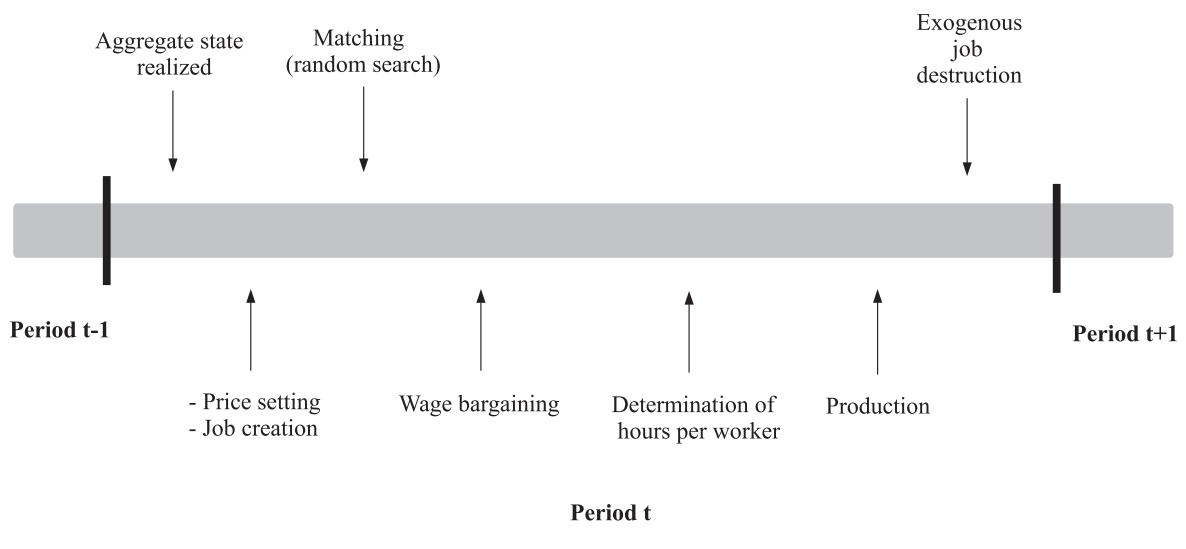

Fig 4. Timing - RTM.

complementarities — and then a very flat NKPC—result from these responses of the marginal wage. The ability of the Nash bargaining and the credible bargaining to reproduce the low volatility of the inflation rate therefore means that the indirect effect dominates the direct effect: the sharp responses of the marginal wage result in large movements along a very flat NKPC.

\section{RIGHT TO MANAGE AND COMPETITIVE SEARCH EQUILIBRIUM}

We finally consider two important modifications of the basic framework.

\subsection{Right To Manage}

Recall that in the baseline framework exposed in Section 1, firms are assumed to choose hours per worker before the wage negotiation occurs, taking rationally into account that a marginal change in hours per employee will imply a change in the bargained average wage. Hence, the marginal and average wages are not equal and can display different cyclical pattern. In the Right-To-Manage framework (henceforth RTM), initially developed by Trigari (2006), firms are instead assumed to choose hours per worker after the average wage was negotiated. The sequence of events is described by Figure 4.

Under RTM, firms can hire each additional hour per employee at the current average wage. The first-order condition with respect to hours per worker for firm $i$ is now given by

$$
m c_{i t} \alpha A_{t} h_{i t}^{\alpha-1}=w_{i t}
$$


instead of equation (5). Thus, we have $\omega_{i t}=w_{i t} \forall t$, which means that the marginal wage is driven by the average wage. Within this set-up, we implement the three wage bargains described in Section 1 . So as to ease this implementation, we assume that the expression of the average wage for each of these wage bargains is the same as in Section $1 .^{29}$ The real average wage, and then the real marginal wage, is consequently given by equation (9) for the Nash bargaining, by equation (11) for the credible bargaining and by equation (13) for the wage norm.

Table 4 makes clear that the RTM fails to reproduce labor-market dynamics, whatever the wage bargain. Even for the credible bargaining the results are at odds with the data. This is consistent with the argument advanced throughout this paper: when firms determine both employment and hours per worker, it is required that the marginal wage be much more responsive than the average wage to shocks. The fact that these two wages display exactly the same pattern explains why the results obtained with the RTM are poor.

\subsection{Competitive Search Equilibrium}

In the baseline framework of Section 1 (as well as in the RTM framework of the previous subsection), the average wage is assumed to be determined $a f$ ter the (random search) matching process. In contrast, in Competitive Search Equilibrium (henceforth CSE, initiated by Moen 1997), the average wage is determined before the (directed search) matching process. In this latter case, the average wage is posted by firms (and no subject to negotiation thereafter). Here, we follow the guidelines proposed by Arseneau and Chugh (2008, Section 7) and modify the baseline framework in order to make it consistent with CSE.

We notably assume that hiring is "instantaneous," that is, a newly employed worker starts working immediately. ${ }^{30}$ Employment at firm level is thus given by

$$
n_{i t}=(1-s) n_{i t-1}+q\left(\theta_{t}\right) v_{i t}
$$

instead of equation (4). The unemployment value now writes:

$$
U_{t}=b+E_{t} \beta_{t, t+1}\left[f\left(\theta_{t+1}\right) W_{i t+1}+\left(1-f\left(\theta_{t+1}\right)\right) U_{t+1}\right],
$$

29. For the RTM, this assumption means that firms and workers bargain over the average wage taking as given subsequent hiring decisions. Such an assumption is notably made by Moene and Wallerstein (2010) and Jimeno and Thomas (2013), when the wage bargaining takes place at the sector level. Note that this simplifying assumption has no significant impact on the results.

30. Assuming instantaneous hiring considerably simplifies the determination of the equilibrium average wage, and allows to express this latter as a variant of the Nash-bargained average wage. At the same time, Thomas (2011, p.1141, footnote 9) points out that with instantaneous hiring, and under the maintained assumption of linear hiring costs, strategic complementarities are absent (Sveen and Weinke 2009, instead, obtain strategic complementarities by assuming convex hiring costs along with instantaneous hiring). In order to ease the comparison with our previous results, we will assume that the slope of the NKPC for CSE is the same as under Nash bargaining with predetermined employment. As we do not evaluate CSE according to its ability to reproduce inflation dynamics, this assumption is innocuous. 


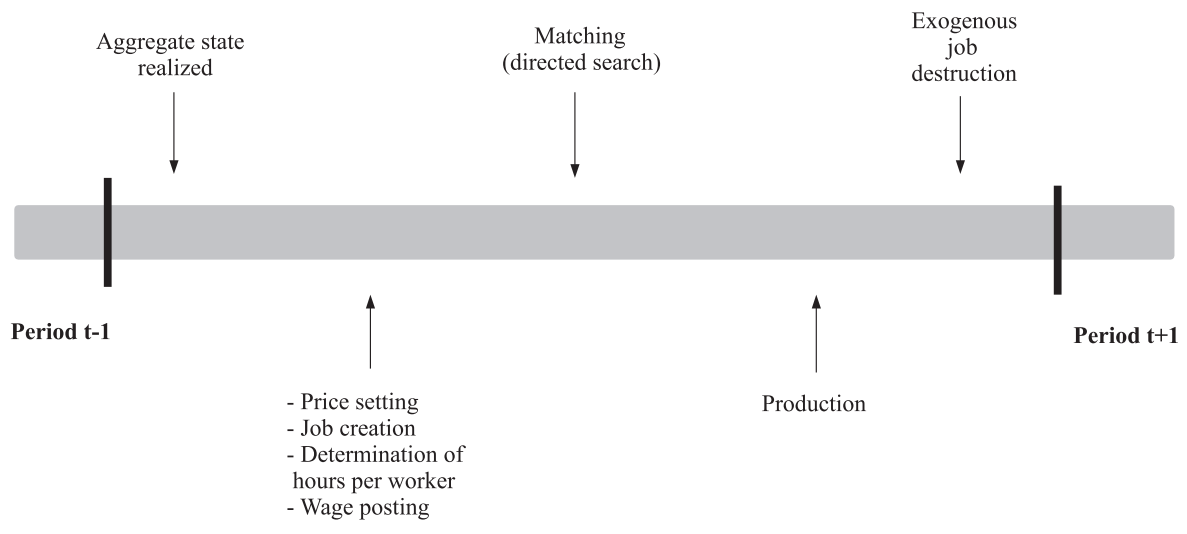

Period t

Fig 5. Timing - CSE

where it is the job-finding rate at time $t+1$ (and not at time $t$ ) that matters.

In CSE, firms search workers within particular "submarkets." At the same time, unemployed workers direct their job search to a particular submarket. Within a given submarket, firms meet the sequence of events described by Figure 5. Firms both choose hours per worker and post wages before the directed search occurs, but rationally take into account the effect of wages on the other side of the market.

The first order condition with respect to hours per worker is the same as in the baseline timing assumption, namely:

$$
m c_{i j t}=\frac{\omega_{i j t}}{\alpha A_{t} h_{i j t}^{\alpha-1}} .
$$

In CSE, matching probability depends on tightness of "applications" at firm $i$ within submarket $j$. The job creation condition for firm $i j$ is thus given by

$$
\frac{\chi}{q\left(\theta_{i j t}\right)}=m c_{i j t} A_{t} h_{i j t}^{\alpha}-w_{i j t} h_{i j t}+E_{t} \beta_{t, t+1}(1-s) \frac{\chi}{q\left(\theta_{i j t+1}\right)}
$$

At the same time, the value of a match for a given worker in firm $i j$ becomes

$$
W_{i j t}=w_{i j t} h_{i j t}-x_{h} \frac{h_{i j t}^{1+\eta}}{(1+\eta) u^{\prime}\left(c_{t}\right)}+E_{t} \beta_{t, t+1}\left[(1-s) W_{i j t+1}+s U_{t+1}\right]
$$

As workers optimally direct their search, the expected payoff of searching for/applying to a job at firm $i j$ is

$$
f\left(\theta_{i j t}\right) W_{i j t}+\left(1-f\left(\theta_{i j t}\right)\right) U_{t}=X,
$$


where $X$ is the payoff of searching at another firm or another submarket.

Firm $i j$ maximizes (26) with respect to $w_{i j t}$ and $\theta_{i j t}$, taking (27) as a constraint, FOCs are

$$
\begin{aligned}
& \phi_{i j t}=-\frac{q\left(\theta_{i j t}\right)}{f\left(\theta_{i j t}\right)}, \\
& \frac{\partial q\left(\theta_{i j t}\right)}{\partial \theta_{i j t}}\left[m c_{i j t} A_{t} h_{i j t}^{\alpha}-w_{i j t} h_{i j t}+E_{t} \beta_{t, t+1}(1-s) \frac{\chi}{q\left(\theta_{i j t+1}\right)}\right] \\
& -\phi_{i j t} \frac{\partial f\left(\theta_{i j t}\right)}{\partial \theta_{i j t}}\left[W_{i j t}-U_{t}\right]=0,
\end{aligned}
$$

where $\phi_{i j t}$ is the Lagrange multiplier of constraint (27). Moreover, the first term in brackets in (29) corresponds to $J_{i j t}$, the value of a filled job for firm $i j$ at time $t$. Combining (28) with (29), and recalling the form of the matching function $\left(m\left(u_{t}, v_{t}\right)=\right.$ $\left.m_{0} u_{t}^{1-\varsigma} v_{t}^{\varsigma}\right)$, implies

$$
\varsigma\left(W_{i j t}-U_{t}\right)=(1-\varsigma) J_{i j t},
$$

which is exactly the Nash-bargained sharing rule with knife-edge Hosios condition $(\varsigma=1-\zeta)$.

The last column of Table 4 displays the results for CSE. The volatility of the unemployment and vacancy rates is low. This stems from the fact that the solution for CSE corresponds to that of Nash bargaining. In addition, the Hosios condition entails a relatively large bargaining power for workers $(\zeta=0.4)$, very close to the value we have assumed in the calibration of the baseline framework $(\zeta=0.5)$. Therefore, the average wage responds to shocks nearly as much as the marginal wage, inducing weak fluctuations in the wage gap.

\section{CONCLUSION}

We have argued that NK models for which firms unilaterally adjust both margins of labor are able to reproduce the dynamics of the labor market in the United States. A necessary condition is that the marginal wage must be much more responsive than the average wage to shocks. We have considered an NK model with labor-market matching frictions in which firms set employment, hours per worker, and prices. Within this framework, we have shown that the wage bargains that generate a marginal wage much more responsive than the average wage replicate the high volatility of the unemployment and vacancy rates. Moreover, in spite of the large responses of the marginal wage, these wage bargains deliver inflation inertia. 
The larger responses of the marginal wage imply that the value of an additional worker is itself highly responsive to shocks, amplifying the adjustment of labor along the extensive margin. At the same time, these responses induce strong strategic complementarities between price setters, which provide inflation inertia through a flat NKPC.

\section{LITERATURE CITED}

Arseneau, David M., and Sanjay K. Chugh. (2008) "Competitive Search Equilibrium.” International Finance Discussion Papers No. 929, Board of Governors of the Federal Reserve System (U.S.).

Ball, Laurence, and David Romer. (1990) "Real Rigidities and the Non-neutrality of Money." Review of Economic Studies, 57, 183-203.

Balleer, Almut, Britta Gehrke, Wolfgang Lechthaler, and Christian Merkl. (2016) "Does ShortTime Work Save Jobs? A Business Cycle Analysis." European Economic Review, 84, 99122.

Barnichon, Régis. (2010) “Building a Composite Help-Wanted Index.” Economic Letters, 109, $175-8$.

Bils, Mark. (1987) “The Cyclical Behavior of Marginal Cost and Price." American Economic Review, 77, 838-55.

Blanchard, Olivier J., and Peter A. Diamond. (1989) “The Beveridge Curve.” Brookings Papers on Economic Activity, 1989, 1-76.

Blanchard, Olivier J., and Jordi Galí. (2007) "Real Wage Rigidities and the New Keynesian Model." Journal of Money, Credit and Banking, 39, 35-65.

Blanchard, Olivier J., and Jordi Galí. (2010) "Labor Markets and Monetary Policy: A New Keynesian Model with Unemployment." American Economic Journal: Macroeconomics, 2, $1-30$.

Boitier, Vincent, and Antoine Lepetit. (2018) "Reduced Form Wage Equations in the Credible Bargaining Model." Labor Economics, 50, 92-6.

Brueckner, Markus, and Evi Pappa. (2012) "Fiscal Expansions, Unemployment and Labor Force Participation: Theory and Evidence." International Economic Review, 53, 1205-28.

Calvo, Guillermo. (1983) "Staggered Prices in a Utility-Maximizing Framework.” Journal of Monetary Economics, 12, 383-98.

Christiano, Lawrence, Martin Eichenbaum, and Mathias Trabandt. (2016) "Unemployment and Business Cycles." Econometrica, 84, 1523-69.

Christoffel, Kai, and Keith Kuester. (2008) "Resuscitating the Wage Channel in Models with Unemployment Fluctuations.” Journal of Monetary Economics, 55, 865-87.

Christoffel, Kai, and Tobias Linzert. (2010) "The Role of Real Wage Rigidity and Labor Market Rigidities in Inflation Persistence.” Journal of Money, Credit and Banking, 42, 1435-46.

Clarida, Richard, Jordi Galí, and Mark Gertler. (1999) "The Science of Monetary Policy: A New Keynesian Perspective.” Journal of Economic Literature, 37, 1661-707. 
Den, Haan, Wouter J., Garey Ramey, and Joel Watson. (2000) "Job Destruction and Propagation of Shocks." American Economic Review, 90, 482-98.

Dossche, Maarten, Vivien Lewis, and Céline Poilly. (2014) "Employment, Hours and Optimal Monetary Policy.” ECB Working Paper No. 1713.

Faia, Ester. (2008) "Optimal Monetary Policy Rules with Labour Market Frictions.” Journal of Economic Dynamics and Control, 32, 1600-21.

Faia, Ester, Wolfgang Lechthaler, and Christian Merkl. (2014) "Labor Selection, Turnover Costs, and Optimal Monetary Policy." Journal of Money, Credit and Banking, 46, 115-44.

Galí, Jordi. (2008) Monetary Policy, Inflation, and the Business Cycle. Princeton, NJ: Princeton University Press.

Galí, Jordi. (2018) “The State of New Keynesian Economics: A Partial Assessment." Journal of Economic Perspectives, 32, 87-112.

Goodfriend, Marvin, and Robert G. King. (1997) "The New Neoclassical Synthesis and the Role of Monetary Policy." In NBER Macroeconomics Annual 1997, edited by Ben S. Bernanke and Julio Rotemberg, pp. 231-96. Cambridge, MA: MIT Press.

Hall, Robert E. (2005) "Employment Fluctuations with Equilibrium Wage Stickiness." American Economic Review, 95, 50-65.

Hall, Robert E., and Paul R. Milgrom. (2008) "The Limited Influence of Unemployment on the Wage Bargain.” American Economic Review, 98, 1653-74.

Jimeno, Juan F., and Carlos Thomas. (2013) "Collective Bargaining, Firm Heterogeneity and Unemployment.” European Economic Review, 59, 63-79.

Jung, Philip, and Keith Kuester. (2011) "The (Un)Importance of Unemployment Fluctuations for the Welfare Cost of Business Cycles." Journal of Economic Dynamics and Control, 35, 1744-68.

Kaplan, Greg, and Guido Menzio. (2016) "Shopping Externalities and Self-Fulfilling Unemployment Fluctuations." Journal of Political Economy, 124, 771-825.

Kimball, Miles S. (1995) "The Quantitative Analytics of the Basic Neomonetarist Model." Journal of Money, Credit and Banking, 27, 1241-77.

Krause, Michael U., and Thomas A. Lubik. (2007) "The (Ir)Relevance of Real Wage Rigidities in the New Keynesian Model with Search Frictions." Journal of Monetary Economics, 54, $706-27$.

Merz, Monika. (1995) "Search in the Labor Market and the Real Business Cycle." Journal of Monetary Economics, 36, 269-300.

Moen, Espen R. (1997) “Competitive Search Equilibrium.” Journal of Political Economy, 105, 385-411.

Moene, Karl O., and Michael Wallerstein. (1997) "Pay Inequality." Journal of Labor Economics, 15, 403-30.

Monacelli, Tommaso, Roberto Perotti, and Antonella Trigari. (2010) "Unemployment Fiscal Multipliers." Journal of Monetary Economics, 57, 531-53.

Nash, John. (1953) “Two-Person Cooperative Games.” Econometrica, 21, 128-40.

Ravenna, Federico, and Carl E. Walsh. (2012) "Monetary Policy and Labor Market Frictions: A Tax Interpretation." Journal of Monetary Economics, 59, 180-95. 
Rotemberg, Julio J. (2008) "The Determination of Weekly Hours of Work: A Comment on Christoffel and Kuester's "Resuscitating the Wage Channel in Models with Unemployment Fluctuations"." Journal of Monetary Economics, 55, 888-91.

Shimer, Robert. (2005) "The Cyclical Behavior of Equilibrium Unemployment and Vacancies." American Economic Review, 95, 25-49.

Silva, José I., and Manuel Toledo. (2009) "Labor Turnover Costs And The Cyclical Behavior of Vacancies And Unemployment." Macroeconomic Dynamics, 13, 76-96.

Snower, Dennis J., and Christian Merkl. (2006) "The Caring Hand that Cripples: The East German Labor Market after Reunification.” American Economic Review, 96, 375-82.

Sveen, Tommy, and Lutz Weinke. (2008) "New Keynesian Perspectives on Labor Market Dynamics." Journal of Monetary Economics, 55, 921-30.

Sveen, Tommy, and Lutz Weinke. (2009) "Inflation and Labor Market Dynamics Revisited." Journal of Monetary Economics, 56, 1096-100.

Thomas, Carlos. (2011) "Search Frictions, Real Rigidities, and Inflation Dynamics." Journal of Money, Credit and Banking, 43, 1131-64.

Trigari, Antonella. (2006) "The Role of Search Frictions and Bargaining for Inflation Dynamics.” IGIER Working Paper No. 304.

Trigari, Antonella. (2009) "Equilibrium Unemployment, Job flows and Inflation Dynamics." Journal of Money, Credit and Banking, 41, 1-33.

Walsh, Carl E. (2005) “Labor Market Search, Sticky Prices, and Interest Rate Policies.” Review of Economic Dynamics, 8, 829-49.

Woodford, Michael. (2003) Interest and Prices: Foundations of a Theory of Monetary Policy. Princeton, NJ: Princeton University Press.

Woodford, Michael. (2005) "Firm-Specific Capital and the New-Keynesian Phillips Curve." International Journal of Central Banking, 1, 1-46.

\section{SUPPORTING INFORMATION}

Additional supporting information may be found online in the Supporting Information section at the end of the article.

Technical Appendix 